\title{
Estratégias de manejo da oferta de forragem para recria de novilhas em pastagem natural
}

\author{
Fabio Pereira Neves ${ }^{1}$, Paulo César de Faccio Carvalho ${ }^{1}$, Carlos Nabinger ${ }^{1}$, Aino Victor Ávila \\ Jacques $^{1}$, Igor Justin Carassai ${ }^{1}$, Fabio Tentardini ${ }^{1}$ \\ ${ }^{1}$ Universidade Federal do Rio Grande do Sul - UFRGS. Av. Bento Gonçalves, 7712. CEP 91501-970, Porto Alegre, RS, Brasil.
}

\begin{abstract}
RESUMO - O experimento foi realizado com o objetivo de avaliar o desenvolvimento de novilhas de corte dos 15 aos 28 meses de idade mantidas em pastagem natural sob diversos manejos da oferta de forragem. Avaliaram-se quatro ofertas fixas ao longo do ano (4, 8; 12 e 16\% do peso vivo, PV) e três ofertas de forragem variáveis (8-12; 12-8; e 16-12\%, de modo que o primeiro valor corresponde à oferta utilizada na primavera e o segundo àquela empregada no restante do ano). Foram utilizadas novilhas de corte mestiças sob pastejo contínuo com taxa de lotação variável para avaliação do peso vivo, do escore de condição corporal, do ganho médio diário e da aptidão reprodutiva pela dosagem de progesterona no sangue. Para caracterização do pasto, foram avaliadas a massa de forragem (MF), a altura do pasto (ALT) e a área efetivamente pastejada (AEP). Na oferta de forragem de $4 \%$, os animais apresentaram redução acentuada de peso no fim do verão e outono, por isso, essa oferta de forragem foi eliminada. O peso vivo, o escore de condição corporal e o ganho médio diário não diferiram entre as ofertas de forragem; as variações ocorreram somente entre as estações. Aos 26 meses de idade, a probabilidade de estro das novilhas não diferiu entre as ofertas de forragem, embora a oferta de forragem de $16-12 \%$ tenha resultado em probabilidade de estro de $50 \%$. Aos 28 meses de idade, a oferta de forragem de 16-12\% resultou em maior probabilidade de estro (86\%) e não diferiu das ofertas de $16 \%$ (50\%) e $8-12 \%$ (50\%), as quais promoveram estrutura do pasto mais adequada, ou menos limitante, ao hábito de pastejo das novilhas.
\end{abstract}

Palavras-chave: ajuste de lotação, aptidão reprodutiva, estrutura do pasto, progesterona

\section{Herbage allowance management strategies to raise beef heifers on natural pastures}

\begin{abstract}
The experiment was carried out to evaluate the development of beef heifers from 15 to 28 months of age, maintained on natural pasture under different herbage allowance (HA) managements. The treatments were fixed HA of $4,8,12$ and $16 \%$ of the body weight (BW) over the year, and variable HA of $8-12 \%$; $12-8 \%$; and 16-12\%, where the first value corresponded to the HA used in the spring and the second one to that used in the remainder of the year. Crossbreed beef heifers were used under continuous stocking with variable stocking rate, and the body weight, body condition score (BCS), average daily gain (ADG) and reproductive ability by blood progesterone concentration were evaluated. In addition, herbage mass, sward height, and effectively grazed area were evaluated to characterize the pasture. At 4\%-HA the animals presented great decrease in weight at the end of summer and fall, and this HA removed from the experiment. Differences among HA were not verified among treatments for LW, BCS, and ADG. At 26 months of age, no difference for heifers estrus probability (EP) was detected, although HA of $16-12 \%$ showed EP of 50\%. At 28 months of age, the HA 16-12\% HA showed greater EP (86\%) and was not different from the HA of $16 \%$ (50\%) and 8-12\% (50\%). Such management strategies promoted a sward structure that was more adequate, or less limited, to heifer grazing.
\end{abstract}

Key Words: progesterone, reproductive aptitude, stocking management, sward structure

\section{Introdução}

Em sistemas de produção de gado de corte, a recria de novilhas é muitas vezes preterida, em decorrência do crescimento dos machos destinados ao abate, os quais geralmente têm acesso a melhores pastos e ofertas de forragem. Esse é um quadro comum em muitas propriedades rurais e resulta em atraso na idade ao primeiro acasalamento. Segundo Lobato (2003), esse equívoco estratégico constitui uma das principais causas da baixa eficiência produtiva da maior parte dos rebanhos no Brasil.

As alternativas a serem utilizadas neste sistema de produção são facilmente enquadradas dentro das potencialidades das pastagens naturais dos Campos 
Sulinos. Novilhas de corte acasaladas aos 25/26 meses de idade não requerem altas taxas de ganho de peso no segundo inverno pós-desmame quando bem criadas no primeiro ano. Segundo Beretta \& Lobato (1998), ganhos de peso entre 0,4 e 0,8 kg/dia observados na fase inicial da recria são suficientes para que a maturidade sexual de fêmeas de corte para o primeiro serviço ocorra aos 25/26 meses de idade.

O manejo da oferta de forragem (OF) constitui um dos parâmetros determinantes das produções primária e secundária dos ecossistemas pastoris e, no caso da pastagem natural, é diretamente responsável pela sua sustentabilidade (Carvalho et al., 2006). A utilização de diferentes níveis de oferta de forragem pode determinar composições botânicas e estruturas de vegetação distintas, assim como diferentes ganhos de peso vivo (PV) por animal e por área (Moojen \& Maraschin, 2002; Crancio et al., 2006; Carvalho et al., 2007).

Em ambientes heterogêneos, como as pastagens naturais, o uso de alterações da oferta de forragem em determinadas épocas do ano depende da manipulação da fenologia e, sobretudo, da estrutura do pasto, uma vez que a redução da oferta de forragem na primavera, estação de maior crescimento, promove o consumo do pasto produzido, evitando sobras e mantendo maior proporção de folhas verdes que permanecem por mais tempo em estádio vegetativo. A hipótese estudada é que o manejo da oferta de forragem é determinante da quantidade e da estrutura do pasto e pode interferir no desenvolvimento da novilha no segundo ano de recria. Neste contexto, objetivou-se avaliar o desenvolvimento de novilhas de corte dos 15 aos 28 meses mantidas em pastagem natural e manejadas sob níveis fixos ou combinações estacionais de oferta de forragem.

\section{Material e Métodos}

O experimento foi conduzido em uma área de 52 ha de pastagem natural na Estação Experimental Agronômica, pertencente à Universidade Federal do Rio Grande do Sul (EEA - UFRGS), localizada no município de Eldorado do Sul, região fisiográfica da Depressão Central do estado do Rio Grande do Sul. As coordenadas geográficas aproximadas da área experimental são $30^{\circ} 05^{\prime} 27 " \mathrm{~S}, 51^{\circ} 40^{\prime} 18^{\prime \prime} \mathrm{W}$ e $46 \mathrm{~m}$ de altitude. O clima da região é do tipo $\mathrm{Cfa}$, subtropical úmido com verão quente, segundo classificação de Köppen. A precipitação total média anual na estação experimental é de $1.440 \mathrm{~mm}$ (Bergamaschi et al., 2003), as temperaturas médias mensais variam entre 9 e $25^{\circ} \mathrm{C}$ e a média diária de radiação solar global entre 200 e $500 \mathrm{cal} / \mathrm{cm}^{2}$.

O experimento teve início em 21/1/2006 após diferimento de 70 dias. A área experimental foi manejada sempre sob lotação contínua com bovinos, ovinos e equinos, seguindo mesmo manejo aplicado há 21 anos. Na primavera de 1986, foram aplicados quatro níveis de oferta de forragem: 3, 6, 9 e 12\% (kg de MS/100 kg de peso vivo) (Maraschin, 1988; Escosteguy, 1990). Na primavera seguinte, os níveis foram modificados para 4, 8, 12 e 16\%, mantendo essas ofertas em sucessivos experimentos durante 14 anos. A partir do ano 2000, foram introduzidas ofertas variáveis ao longo do ano, aumentando ou diminuindo a oferta de forragem na primavera conforme a estratégia de manejo preconizada. Assim, as ofertas de forragem foram definidas até a realização deste trabalho da seguinte forma: 4; 8; 12 ou $16 \%$ do PV durante todo o ano; $8 \%$ do PV na primavera e $12 \%$ do PV no verão/outono/inverno; $12 \%$ do PV na primavera e $8 \%$ do PV no verão/outono/inverno; $16 \%$ do PV na primavera e $12 \%$ do PV no verão/outono/inverno.

Em 7/10/2006, as ofertas de forragem de primavera foram alteradas e mantidas até o dia 13/1/2007, quando se retornaram aos níveis de oferta de forragem do restante do ano. O período experimental teve duração de 388 dias, com início em 21/1/2006 e 13/2/2007. Durante o verão (21/1/2006 a 30/3/2006) e outono (31/3/2006 a 13/6/2006), a baixa reserva corporal das novilhas, associada à baixa massa de forragem nos piquetes com oferta de forragem de 4\% (MF abaixo de $500 \mathrm{~kg} / \mathrm{ha}$ de MS e altura de $3 \mathrm{~cm}$ ), acarretou a necessidade de retirada dos animais visando manutenção da integridade física dos animais, uma vez que houve óbito devido à baixa oferta de forragem empregada (OF 4\%). Portanto, os dados obtidos com a oferta de forragem de $4 \%$ encontram-se apenas nas tabelas e figuras com os dados por estação, somente no verão e no outono de 2006, e não foram incluídos no conjunto de dados para análise estatística.

A estimativa da massa de forragem ( $\mathrm{kg} / \mathrm{ha}$ de MS) em cada unidade experimental foi obtida utilizando-se a técnica de dupla amostragem descrita por Wilm et al. (1944), de modo que as amostras foram estimadas com auxílio de um quadrado de ferro de $0,25 \mathrm{~m}^{2}$, totalizando 50 pontos amostrais exclusivamente no estrato inferior da pastagem (área efetivamente pastejada, \% do total), excluindo as touceiras com espécies indesejáveis, conforme definição apresentada por Fontoura Jr. et al. (2007). Além dos 50 pontos estimados no caminhamento, foram estimados e cortados com tesoura de esquila elétrica mais quatro pontos acima do mantilho; as amostras foram recolhidas em sacos de papel, secas em estufa ventilada a $65^{\circ} \mathrm{C}$ por 72 horas e pesadas em balança de precisão. Após a secagem, essas amostras foram trituradas em moinho tipo Willey com peneira de malha de $1,0 \mathrm{~mm}$ e acondicionadas em sacos plásticos para posteriores análises laboratoriais. Os valores dos cortes foram utilizados para ajuste das estimativas visuais da massa de forragem em 
cada avaliação. Durante esse caminhamento, também foi registrada a frequência de touceiras de espécies e/ou estruturas pré-definidas como indesejáveis e sua participação percentual foi descontada para se obter a estimativa do percentual de área efetivamente pastejada (AEP). No centro das amostras para estimativa visual da massa de forragem, mediu-se a altura do pasto $(\mathrm{cm})$ com auxílio de um bastão graduado, segundo método proposto por Barthram (1985).

O procedimento de pesagem dos animais e as avaliações feitas no pasto foram realizados sempre em intervalos de 28 dias. A taxa de acúmulo diária de matéria seca (TAC) foi medida com o uso de quatro gaiolas de exclusão ao pastejo por unidade experimental, empregando-se a técnica do triplo emparelhamento (Moraes et al., 1990). A disponibilidade de forragem diária (kg/ha de MS) foi calculada pelo quociente entre a massa de forragem inicial e final pelo número de dias de cada subperíodo experimental, mais a TAC correspondente. A oferta real de forragem (kg de MS/ $100 \mathrm{~kg}$ de PV) foi obtida dividindo-se a disponibilidade diária de forragem pela taxa de lotação média de cada subperíodo, em kg/ha de PV, de modo que o valor obtido foi multiplicado por 100 para expressar a oferta diária em porcentagem do peso vivo (\% do PV).

Em cada unidade experimental, foram incluídos três animais-teste e um número variável de reguladores. Foram utilizadas novilhas oriundas de cruzamentos entre as raças Angus, Hereford e Nelore, provenientes da empresa Agropecuária Cerro Coroado (Cachoeira do Sul, Rio Grande do Sul), com idade e peso médio inicial de 15 meses e $188 \mathrm{~kg}$, respectivamente. Os animais foram previamente classificados e agrupados por peso vivo e tipo racial e, respeitando esses critérios, foram sorteados entre as unidades experimentais. O método de pastejo utilizado foi o contínuo com taxa de lotação variável, empregando-se a técnica do uso de animais reguladores (Mott \& Lucas, 1952) para ajuste da lotação à oferta de forragem preconizada.

Por ocasião das pesagens, após jejum prévio de 12 horas, as novilhas foram submetidas à avaliação da condição corporal e classificadas em escores de 1,0 a 5,0, em que 1 = muito magro e 5 = muito gordo (Lowman et al., 1973). $\mathrm{O}$ ganho médio diário $(\mathrm{kg})$ foi obtido pelo quociente da diferença de peso entre duas pesagens sucessivas pelo número de dias desse intervalo. Para avaliação da aptidão reprodutiva das novilhas, utilizou-se a dosagem de progesterona para detectar atividade cíclica regular, em datas de coleta correspondentes aos 20, 22, 24, 26 e 28 meses de idade. Foram coletadas duas amostras de sangue em intervalos de 10 dias, obtidas por punção da veia ou artéria coccígea e alocadas em frascos contendo anticoagulante (heparina). Imediatamente após as coletas, as amostras de sangue foram centrifugadas a $3.000 \mathrm{rpm}$ durante 10 minutos e os plasmas obtidos foram identificados quanto ao animal e à data da coleta, acondicionados em tubos tipo eppendorf e armazenados em freezer a $-18^{\circ} \mathrm{C}$ até o momento das dosagens de progesterona. As concentrações de progesterona foram analisadas por radioimunoensaio (RIA) com a utilização de kits comerciais (ICN PHARMACEUTICALS, INC), em aparelho cintilador gama Cobra II. Foi considerada com atividade cíclica regular a novilha com nível de progesterona no sangue igual ou superior a $1 \mathrm{ng} / \mathrm{mL}$ em cada uma das coletas.

O delineamento experimental utilizado foi o de blocos completos casualizados com medidas repetidas no tempo, com duas repetições de área por oferta de forragem, utilizando o tipo de solo como critério de bloqueamento. Os dados foram submetidos à análise de variância e ao teste F pelo Mixed Procedure (PROC MIXED) do pacote estatístico SAS (2001). Para a escolha da matriz de variância e covariância, utilizou-se o critério de informação Akaike (Wolfinger, 1993). As médias dos tratamentos foram estimadas utilizando-se o LSMEANS e a comparação, por meio da probabilidade da diferença (PDIFF) pelo teste $t$ de Student, a 10\% de significância. Os dados de desempenho reprodutivo dos animais foram submetidos à análise de Qui-quadrado no nível de 10\% de significância, pelo Genmod Procedure (PROC GENMOD), adotando-se para essa variável distribuição binomial (ciclando ou não ciclando).

\section{Resultados e Discussão}

Na média do período experimental, as ofertas reais de forragem diferiram $(\mathrm{P}=0,0116)$ e apresentaram valores próximos aos das ofertas de forragem pretendidas, o que resultou no gradiente previsto entre os níveis e as combinações de oferta de forragem (Tabela 1), condição básica para testar a hipótese de trabalho. Além disso, houve efeito da oferta de forragem sobre a massa de forragem $(\mathrm{P}=0,0705)$, a altura do pasto $(\mathrm{P}=0,0354)$ e a área efetivamente pastejada $(\mathrm{P}=0,0705)$. A taxa de lotação não diferiu $(\mathrm{P}=0,1200)$ entre as estratégias de manejo da oferta de forragem.

O percentual de área efetivamente pastejada (AEP) representa a fração de área composta pelo estrato inferior, onde se concentram os sítios alimentares preferidos (Stuth, 1991). A fração restante corresponde à área ocupada, sobretudo por espécies indesejáveis e/ou por estruturas menos aceitas pelo animal. A correlação entre área efetivamente pastejada e oferta real de forragem foi de -0,38594 ( $P=0,0023$ ), o que indica aumento na presença de touceiras e redução da superfície pastoril com o aumento da oferta de forragem. 
Tabela 1 - Oferta real de forragem, massa de forragem, altura do pasto, área efetivamente pastejável e taxa de lotação em pastagem natural sob diferentes estratégias de manejo da oferta de forragem

\begin{tabular}{|c|c|c|c|c|c|}
\hline $\begin{array}{l}\text { Oferta de forragem } \\
(\% \mathrm{PV})\end{array}$ & $\begin{array}{c}\text { Oferta real de } \\
\text { forragem }(\% \mathrm{PV})\end{array}$ & $\begin{array}{c}\text { Massa de } \\
\text { forragem (kg/ha de MS) }\end{array}$ & $\begin{array}{l}\text { Altura do } \\
\text { pasto }(\mathrm{cm})\end{array}$ & $\begin{array}{c}\text { Área efetivamente } \\
\text { pastejada (\%) }\end{array}$ & $\begin{array}{c}\text { Taxa de lotação } \\
\text { (kg/ha de PV) }\end{array}$ \\
\hline $8 \%$ & $8,4 \mathrm{D}(0,85)$ & $1.170 \mathrm{D}(127,4)$ & 5,5D $(0,58)$ & 76,9 AB $(0,35)$ & $417,8(0,35)$ \\
\hline $16 \%$ & $16,2 \mathrm{~A}(0,93)$ & $1.935 \mathrm{AB}(130,8)$ & $9,3 \mathrm{AB}(0,60)$ & $62,8 \mathrm{C}(0,63)$ & $300,4(0,35)$ \\
\hline $8-12 \%$ & $9,8-12,4 \mathrm{BC}(1,02)$ & 1.640BC $(131,20)$ & $7,6 \mathrm{BC}(0,60)$ & $78,4 \mathrm{~A}(0,36)$ & $404,3(0,35)$ \\
\hline $12-8 \%$ & $11,4-8,4 \mathrm{D}(0,92)$ & $1.350 \mathrm{CD}(128,9)$ & $6,8 \mathrm{CD}(0,59)$ & $70,1 \mathrm{BC}(0,70)$ & $376,2(0,35)$ \\
\hline $16-12 \%$ & $15,2-14,5$ АВ $(0,93)$ & $2.050 \mathrm{~A}(128,4)$ & $9,5 \mathrm{~A}(0,59)$ & $65,1 \mathrm{C}(0,65)$ & $356,3(0,35)$ \\
\hline
\end{tabular}

Médias com letras distintas nas colunas diferem $(\mathrm{P}<0,10)$ pelo teste $\mathrm{t}$.

Verificou-se queda de 76,9 para 62,8\% na área efetivamente pastejada entre as oferta de forragem de $8 \%$ PV e a de 16\% PV durante todo o ano. Santos (2007) observou o mesmo fenômeno e afirmou que essa diminuição é acentuada entre as ofertas de forragem de 4 e $12 \%$ (de $95-100 \%$ para 65-70\%, aproximadamente) e apresenta relativa estabilização da frequência de touceiras a partir da oferta de forragem de $12 \%$. Neste trabalho, as menores ofertas de forragem foram a de $8 \%$ fixa e suas combinações, cujos percentuais de área efetivamente pastejada foram os mais altos, com exceção da oferta de forragem de $12-8 \% \mathrm{PV}$. Contudo, as ofertas de forragem $8 \%$ e $12-8 \%$ resultaram nas menores massas de forragem e alturas. A oferta de forragem de $12 \%$ não diferiu daquelas de 16 e 16-12\% PV e, a partir desse nível, apresentou comportamento semelhante.

A oferta de forragem de 8-12\% PV resultou em área efetivamente pastejada semelhante à obtida com oferta de forragem de $8 \%$ PV e superou aquela com 12-8\% PV. Essa estratégia parece ser positiva por manter percentual de área efetivamente pastejada relativamente alto, com pouco reflexo na massa de forragem e altura, as quais mantiveram valores médios próximos aos de níveis e combinações de oferta de forragem mais altos, com exceção da oferta de $16-12 \% \mathrm{PV}$. Em tese, isso pode influenciar a resposta animal, pois o animal explora uma pastagem com menor percentual de áreas de rejeição, como as touceiras, e com forragem mais acessível, podendo melhorar o pastejo durante uma refeição e ao longo do dia. Gordon (2000), trabalhando em vegetação natural da Escócia, observou que o padrão de pastejo dos animais está intimamente relacionado à dinâmica dos estratos inferior e superior da pastagem, cuja condição e frequência dependem das intensidades de pastejo empregadas.

A inexistência de diferença na taxa de lotação entre as ofertas de forragem pode ser atribuída às diferenças na massa de forragem estimada exclusivamente no estrato inferior, que não apresentam magnitudes suficientes para ocasionar diferenças significativas em lotação animal; e às alterações estacionais da oferta de forragem, que permitem momentos de maior ou menor lotação, entretanto, na média anual, essas respostas são compensadas.

Ambientes complexos, como as pastagens naturais, caracterizam-se pela formação de diferentes estruturas vegetacionais, consequência de sua diversidade florística e de condições de solo e relevo (Pallarés et al., 2005). O manejo dessa heterogeneidade espacial, resultante da manutenção de oferta de forragem em níveis moderados a altos, constitui o maior desafio para a pesquisa em pastagem natural (Soares, 2002). Além disso, de acordo com Santos (2007), as alterações estruturais não se resumem apenas à divisão bimodal da vegetação. Segundo o autor, no estrato efetivamente pastejado, mesmo quando considerado exclusivamente, ocorrem alterações em estrutura que podem afetar o comportamento ingestivo dos animais. Pinto et al. (2007), trabalhando com o mesmo protocolo experimental, não notaram diferenças no tempo de pastejo de novilhos entre os níveis de oferta de forragem. Entretanto, a resposta foi significativa quando avaliaram esse parâmetro considerando a altura do estrato efetivamente pastejado da pastagem.

Para o melhor entendimento do perfil do estrato efetivamente pastejado (Figuras 1 e 2) e para se fazer inferências de possíveis relações entre a estrutura do pasto e a resposta animal, foram adicionadas linhas contínuas que delimitam faixas em intervalos de $2 \mathrm{~cm}$ e $500 \mathrm{~kg} / \mathrm{ha}$ de MS nos intervalos de 6 a $12 \mathrm{~cm}$ e de 1.000 a $2.500 \mathrm{~kg} /$ ha de MS, respectivamente, para altura do pasto e massa de forragem.

Com a manutenção do nível de oferta de forragem de 8\% durante $\mathrm{o}$ ano, a tendência da altura média do pasto (Figura 1) foi de manter-se em um patamar abaixo da faixa de $6,0 \mathrm{~cm}$ (média anual de 5,5 cm), salvo no verão de 2006 (7,5 cm), em virtude do efeito do diferimento de 70 dias antes do início do experimento. Nas demais estações, a altura média manteve-se em torno de 5,0 cm e baixou mais no verão de 2006/2007, provavelmente em decorrência dos reflexos de uma estiagem. Segundo Maraschin (2001), com oferta de forragem de $8 \%$, o pasto apresenta rebrote ativo e intenso, mas a elevada intensidade de pastejo não permite 


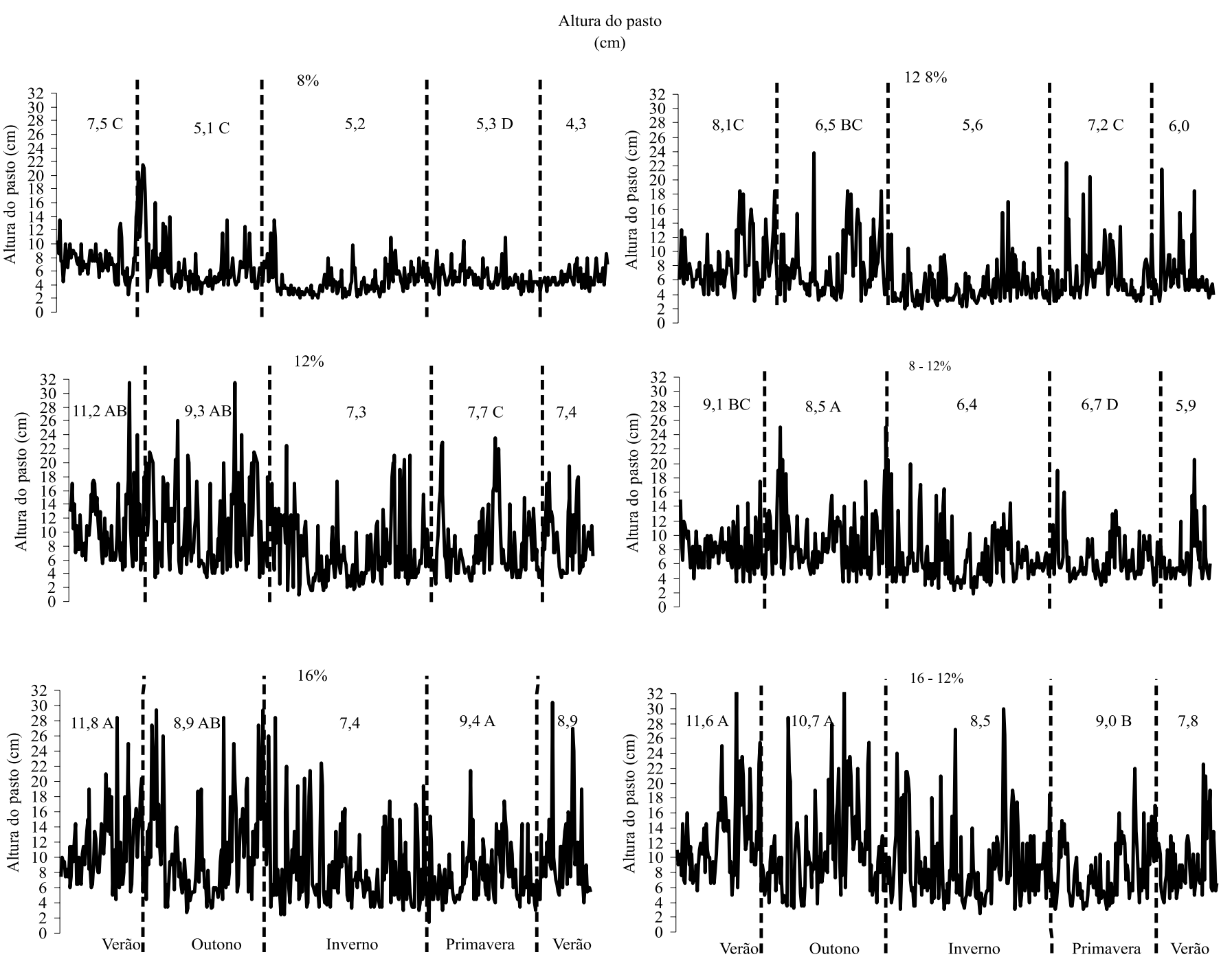

Médias seguidas de letras distintas, na mesma estação do ano, diferem pelo teste Pdiff a $10 \%$.

Figura 1 - Distribuição anual e médias por estação dos pontos amostrais de altura do pasto em pastagem natural sob diferentes estratégias de manejo da oferta de forragem.

a manutenção de uma estrutura (como a massa de forragem e altura do pasto) que beneficie o tempo em pastejo.

Na oferta de forragem com $12 \%$ no período da primavera e $8 \%$ do PV no restante do ano, houve um impacto na estrutura, que tendeu a se manter nas demais estações do ano, resultando em pastos com valores médios de altura e massa de forragem do estrato inferior um pouco maiores que os observados com a oferta de forragem de $8 \%$ PV durante todo o ano, pois ocasionou aumento médio de $2 \mathrm{~cm}$ em altura e $200 \mathrm{~kg} / \mathrm{ha}$ de MS na massa de forragem (Figuras 1 e 2).

Não obstante, a maior frequência da altura e massa de forragem ainda se manteve na faixa de 4 a $7 \mathrm{~cm}$ e de 900 a $1.400 \mathrm{~kg} / \mathrm{ha}$ de MS, respectivamente, de modo que a ingestão de forragem provavelmente foi limitada, segundo o modelo proposto por Gonçalves \& Carvalho (2006) e
Gonçalves (2007). Esse autor, manejando pastagens naturais em diferentes alturas de estrato inferior (4, 8, $12 \mathrm{e}$ $16 \mathrm{~cm}$ ), onde mediu taxa de ingestão instantânea de matéria seca, concluiu que a altura do pasto de 11,4 cm maximizou a taxa de ingestão de novilhas e quase triplicou a velocidade de ingestão em comparação à taxa observada com altura de estrato inferior de $4 \mathrm{~cm}$.

O perfil do pasto com oferta de forragem de $12 \% \mathrm{PV}$ foi mais elevado, 3 a 4 cm a mais em relação àquele da oferta de forragem de 8\% PV: a altura variou de 7,3 a 11,2 cm e a massa de forragem, entre 1.600 e $2.000 \mathrm{~kg} / \mathrm{ha}$ de MS. Durante 14 anos de pesquisa em pastagem natural, a oferta de forragem de $12 \%$ foi justamente a que proporcionou as melhores respostas animais (Maraschin, 2001). Entretanto, após acrescentar ofertas de forragem variáveis, Soares et al. (2005) 


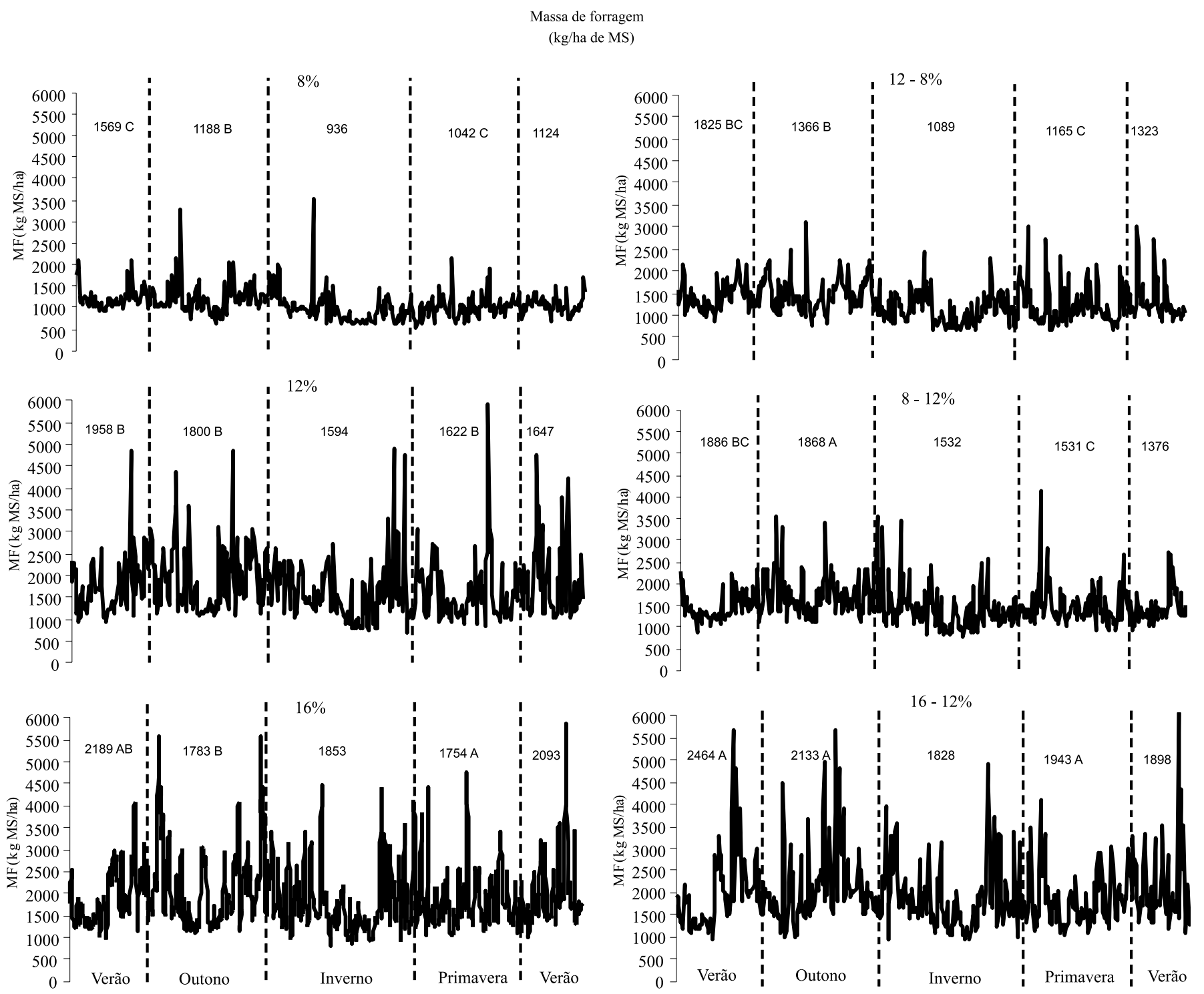

Médias seguidas de letras distintas, na mesma estação do ano, diferem pelo teste Pdiff a $10 \%$.

Figura 2 - Distribuição anual e médias por estação dos pontos amostrais de massa de forragem em pastagem natural sob diferentes estratégias de manejo da oferta de forragem (OF).

constataram superioridade para a oferta de forragem de $8 \%$ PV na primavera e $12 \%$ no verão/outono/inverno. Resposta análoga foi encontrada na oferta de forragem de $12 \%$ (Figuras 1 e 2), porém, com menor variação nos pontos de altura e massa de forragem, em virtude da redução da oferta de forragem na primavera. De acordo com Soares et al. (2005), a alteração da oferta de forragem produz mudanças na vegetação que têm influenciam o período de maior restrição de forragem, como no inverno, quando a oferta de forragem de $8 \%$ na primavera e $12 \%$ promove ganhos de peso positivos.

As ofertas de forragem de $16 \% \mathrm{PV}$ durante todo o ano e de $16 \%$ na primavera e $12 \%$ PV no verão/outono/inverno, apesar de promoverem menor área efetivamente pastejada (Tabela 1), apresentaram maior altura do pasto $(\mathrm{P}<0,1)$ e manteve maiores frequências de pontos de altura em faixas mais adequadas ao consumo. Em trabalho realizado por Santos (2007) neste mesmo protocolo experimental, foram considerados pontos amostrais com massas de forragem entre 1.400 e $2.500 \mathrm{~kg} / \mathrm{ha}$ de matéria seca e altura do pasto entre 7,5 e 13,5 com estações alimentares ótimas, porém esse autor sugeriu maior estudo dessas variáveis, pois são altamente correlacionadas entre si e se correlacionam com a maioria das variáveis de quantidade de forragem disponível, estrutura do pasto, relação forragem lotação e desenvolvimento animal. 
Nestas duas estratégias, houve maior heterogeneidade no estrato efetivamente pastejado (estrato inferior), comprovando que os animais podem estar selecionando ativamente sua dieta. Segundo Baumont et al. (2005), quando a pressão de pastejo é baixa, onde áreas maiores são oferecidas aos animais, a pressão de pastejo efetiva varia espacial e temporalmente. Esse uso desigual da pastagem acarreta maior heterogeneidade na oferta de forragem, cuja percepção de desperdício pode levar a interpretações incorretas sobre o método de pastejo sob lotação contínua (Briske et al., 2008).

Gonçalves \& Carvalho (2006) demonstraram que a massa do bocado e a taxa de ingestão de matéria seca responderam de forma quadrática ao aumento da altura do estrato pastejado. Esses autores observaram que o padrão de ingestão de forragem aumenta na faixa entre 10 e $12 \mathrm{~cm}$ de altura e em massa de forragem entre 2.000 e $2.500 \mathrm{~kg} / \mathrm{ha}$ de MS. Considerando as ofertas de forragem mais altas (16\% durante todo o ano e $16 \%$ PV na primavera e $12 \%$ no verão/ outono/inverno), os valores de altura do pasto e massa de forragem foram em média de 9 e 10 cm e $2.000 \mathrm{~kg} / \mathrm{ha}$ de MS, mais próximos das características desejáveis ao pastejo (Gonçalves \& Carvalho, 2006), o que poderia representar a melhor opção para desempenho animal satisfatório.

O período entre 15 e 20 meses de idade correspondeu às estações do verão e outono de 2006; o período dos 20 aos 24 meses, à estação do inverno; o dos 24 aos 26 meses, à primavera; e dos 26 meses até os 28 meses, ao início do verão de 2007. O peso vivo ( $P=0,5337)$, o escore de condição corporal $(\mathrm{P}=0,5937)$ e o ganho médio diário $(\mathrm{P}=0,6908)$ não diferiram entre as estratégias de manejo da oferta de forragem, mas diferiram entre as estações do ano $(\mathrm{P}<0,0001)$ (Figura 3). A não-significância provavelmente deve-se a um efeito originado da "ruptura estrutural" gerada no perfil do pasto pela ação dos animais e dos gradientes de oferta de forragem impostos, uma vez que, nas maiores ofertas de forragem foram obtidos os menores valores de área efetivamente pastejada.

Quando a pressão de pastejo é baixa, áreas maiores são oferecidas aos animais, fazendo com que a atual pressão de pastejo varie no espaço e no tempo. O uso desigual da pastagem ocasiona aumento da heterogeneidade da biomassa disponível (Baumont et al., 2005) e, no caso de pastagens naturais de dupla estrutura, formam-se touceiras, também definidas como espécies indesejáveis (Fontoura Jr. et al., 2007). De acordo com Marriott \& Carrère (1998), áreas com plantas mais pastejadas diferem de áreas de plantas menos pastejadas, criando padrões espaciais em diferentes escalas. O termo "ruptura estrutural", neste
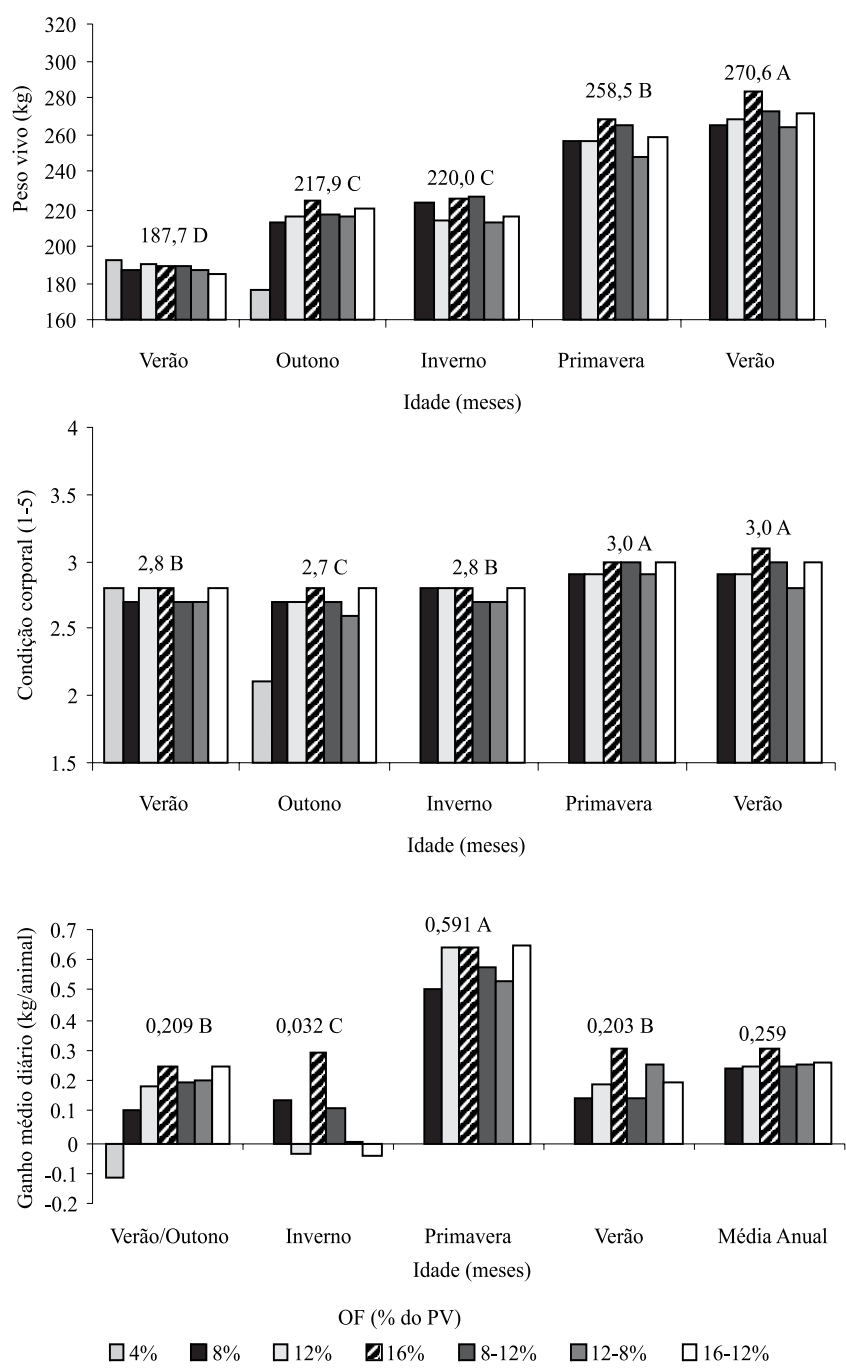

Médias com letras diferentes nas colunas diferem entre estações pelo teste $t \quad(P>0,10)$.

Figura 3 - Peso vivo, escore de condição corporal e ganho médio diário para novilhas de corte entre os 15 e 28 meses de idade mantidas em pastagem natural sob diferentes estratégias de manejo da oferta de forragem (OF, \% PV).

contexto, define que a planta com pouca desfolha vai mudando sua estrutura e qualidade até chegar em um ponto que passa a ser rejeitada pelos animais deixando de ser forragem disponível para tornar locais quase não utilizados pelos animais em pastejo. Quando se diminuíam os níveis de oferta de forragem, aumentava-se a área efetivamente pastejada, entretanto, esse aumento era acompanhado de menores valores de massa de forragem e altura do pasto (Tabela 1).

O peso vivo variou de 187,7 a 258,5 kg PV entre os 15 e 24 meses, respectivamente, na média entre as massas de forragem e chegaram a 270 kg no mês de fevereiro aos 28 
meses de idade (Figura 3A). Na oferta de forragem de 4\% durante todo o ano, observaram-se decréscimo acentuado no peso vivo, no escore de condição corporal e no ganho médio diário do verão para o outono (15-20 meses). As novilhas desse grupo, após a entrada nos piquetes, passaram de 192 para 176 kg PV e de escore de condição corporal 2,8 para 2,1, quando foram retiradas do experimento. Naquele momento, ainda que se alterasse a oferta de forragem retirando os animais reguladores, o pasto dificilmente responderia em aumentos de altura e massa de forragem, pois as taxas de acúmulo nesta época (final de verão/início de outono) são muito baixas (Soares et al., 2005).

Estudando separadamente os períodos entre os 15 e os 20 meses de idade, correspondentes ao verão e outono de 2006 (Figura 3C), observou-se que, no verão, os ganhos médios diários foram de $0,250 \mathrm{~kg}$ na oferta de forragem de $4 \%$ e de $0,550 \mathrm{~kg}$ para média das demais ofertas de forragem, enquanto, no outono, a oferta de forragem de $4 \%$ ocasionou perda de peso de $0,418 \mathrm{~kg} /$ dia e as demais ofertas de forragem, na média, promoveram perda de peso de $0,100 \mathrm{~kg} /$ dia. Dessa forma, os ganhos do período do verão foram significativos, fato que, no caso do acasalamento aos 18 meses, poderia resultar em novilhas com peso e condição corporal adequados, que poderiam conceber sem grandes problemas.

Trabalhando na mesma área experimental com oferta de forragem de 4\%, Santos (2007) observou perda de peso de $-0,200$ e -0,100 kg/animal.dia, respectivamente, no verão e outono, contudo, o peso inicial na ocasião foi de $263 \mathrm{~kg}$, enquanto neste experimento foi de $188 \mathrm{~kg}$. Esse resultado é importante quando se deseja definir a melhor estratégia de manejo da novilha de reposição durante o segundo ano. Portanto, o peso aos 12 meses e a necessidade de ganho de peso para que se atinja o peso-alvo para acasalamento aos 24-26 meses são os principais aspectos a considerar na escolha do manejo mais adequado à pastagem.

O baixo peso das novilhas no início do experimento (188 kg aos 15 meses) pode ser reflexo da deficiência alimentar no primeiro inverno, previamente ao experimento, quando foram mantidas exclusivamente em pastagem natural sem controle da oferta de forragem. O peso-alvo para o início do primeiro serviço está relacionado ao peso da novilha na maturidade, que, por sua vez, depende do grupo racial (Greer et al., 1983) - no grupo de novilhas deste estudo, o peso-alvo foi estimado em $290 \mathrm{~kg}$.

Apesar de o escore de condição corporal ter sido maior aos 26 e 28 meses de idade, sua variação foi relativamente baixa (entre 2,8 e 3,0) (Figura 3B). Em trabalho conduzido por Barcellos et al. (2001), foi demonstrada alta correlação entre a camada de gordura de cobertura e a idade à puber- dade de novilhas de corte. Pilau \& Lobato (2006) reportaram que, no caso da pastagem natural, e em se tratando de novilhas, provavelmente é necessário fornecimento de concentrado proteico-energético para que haja mudança significativa na condição corporal, uma vez que a pastagem natural não atende às exigências desses animais, para ganhos moderados a altos, no período de outono-inverno. Isso significa que são necessárias elevadas taxas de ganho de peso para que ocorra acúmulo de tecido adiposo, além do crescimento ósseo e da deposição muscular.

De acordo com Wiltbank et al. (1985), as novilhas devem ser alimentadas para atingir 65\% do seu PV adulto e condição corporal moderada no início de sua primeira estação de acasalamento. Nesse caso, nenhuma das estratégias de manejo promoveu peso adequado aos 26 meses de idade e, na média das ofertas de forragem, as novilhas apresentavam $258,5 \mathrm{~kg}$. Considerando peso adulto de $450 \mathrm{~kg}$ de PV, na média dos tratamentos, as novilhas apresentavam apenas 57\% do PV adulto aos 26 meses de idade e esse percentual foi limitante à aptidão reprodutiva.

Rocha et al. (2004), em pesquisa com novilhas de corte com peso à desmama de $180 \mathrm{~kg}$, utilizaram pastagem de aveia + azevém no primeiro inverno e, posteriormente, pastagem natural durante o verão, o que permitiu às fêmeas atingirem, aos 18 meses de idade, 58\% do seu peso maduro. Para chegar aos 24 meses com o peso-alvo, seriam necessários apenas $32 \mathrm{~kg}$, ou 0,170 kg/dia por animal, o que seguramente seria obtido em pastagem natural com oferta de forragem moderada. Nota-se, assim, a importância do manejo no primeiro inverno pós-desmama, que, em última análise, determina a taxa de ganho de peso necessária no segundo ano. Dessa forma, a partir do conhecimento da resposta potencial de cada estratégia de manejo, pode-se optar pela mais eficiente para cada situação em particular.

Em outro trabalho conduzido por Rocha et al. (2003) com novilhas de peso médio inferior ao trabalho precedente (120 kg), aquelas que pastejaram aveia + azevém com suplementação energética obtiveram peso vivo médio ao final do ciclo da pastagem de $214 \mathrm{~kg}$. Neste caso, para o acasalamento aos 24 meses, seria necessário ganho médio diário de apenas $0,230 \mathrm{~kg} /$ animal, o que também é possível em pastagem natural manejada com ofertas adequadas (Santos, 2007).

Santos et al. (2004), em pesquisa com novilhas mestiças de raças europeias com peso aos 12 meses entre 180 e $200 \mathrm{~kg}$, estimaram ganho médio diário de $0,205 \mathrm{~kg} /$ animal para que atingissem $65 \%$ do peso adulto aos 24 meses de idade, considerando uma vaca de $420 \mathrm{~kg}$ como peso adulto. Considerando peso vivo de $290 \mathrm{~kg}$ como peso-alvo, as novilhas utilizadas neste trabalho necessitariam de ganho 
Tabela 2 - Probabilidade de estro em novilhas manejadas dos 15 aos 28 meses de idade em pastagem natural sob diferentes estratégias de manejo da oferta de forragem

\begin{tabular}{llc}
\hline Oferta de forragem (\% PV) & \multicolumn{2}{c}{ Idade (meses) } \\
\cline { 2 - 3 } & \multicolumn{2}{c}{26} \\
\hline & \multicolumn{1}{c}{ Probabilidade de estro (\%) } \\
8 & 0,0 & $0,25 \mathrm{~B}$ \\
12 & 0,0 & $0,25 \mathrm{~B}$ \\
16 & 0,125 & $0,50 \mathrm{AB}$ \\
$8-12$ & 0,25 & $0,50 \mathrm{AB}$ \\
$12-8$ & 0,143 & $0,143 \mathrm{~B}$ \\
$16-12$ & 0,500 & $0,86 \mathrm{~A}$ \\
\hline
\end{tabular}

Médias com letras distintas diferem nas colunas pelo teste qui-quadrado (10\%).

de 92 kg de PV até os 24 meses, o que significa ganho médio diário de $0,335 \mathrm{~kg}$ para se chegar aos 2 anos de idade aptas à reprodução. O ganho médio diário neste período (15 aos 26 meses) foi de 0,236 kg e não foi suficiente para assegurar o peso-alvo e escore de condição corporal adequado para o acasalamento aos 24-26 meses de idade.

Nas avaliações realizadas aos 20 e 24 meses de idade, não foram detectadas novilhas em atividade cíclica regular (Tabela 2). Aos 26 meses, não houve influência do manejo da oferta de forragem sobre a probabilidade de estro $(\mathrm{P}=0,113)$, contudo, a oferta de forragem de $16 \%$ na primavera e $12 \%$ no verão/outono/inverno já apresentava, nesta ocasião, probabilidade de ocorrência de atividade cíclica nas novilhas de 0,50 . Aos 28 meses de idade, houve diferença $(P=0,057)$ nas probabilidades entre as ofertas de forragem, uma vez que as ofertas de forragem de $16 \%$ PV na primavera e $12 \%$ no verão/outono/inverno; $16 \% \mathrm{PV}$ durante o ano todo; e $8 \%$ na primavera e $12 \%$ no verão/outono/inverno promoveram os maiores valores de probabilidade de estro. Os resultados corroboram o baixo peso médio das novilhas aos 26 meses, inferior a $260 \mathrm{~kg}$, chegando aos 28 meses com $270 \mathrm{~kg}$, o que representou apenas $60 \%$ do peso adulto estimado (450 kg).

Relacionando os resultados de desempenho animal e aptidão reprodutiva à caracterização estrutural da pastagem (massa de forragem, altura do pasto e área efetivamente pastajada), algumas constatações são relevantes. Embora as estratégias de manejo da oferta de forragem não tenham afetado o peso vivo, o escore de condição corporal e o ganho médio diário, aos 28 meses de idade, as ofertas de forragem de $16 \%$ PV na primavera e $12 \%$ PV no verão/ outono/inverno; de $16 \% \mathrm{PV}$ durante todo o ano; e de $8 \% \mathrm{PV}$ na primavera e $12 \% \mathrm{PV}$ no verão/outono/inverno aumentaram a probabilidade de atividade cíclica regular (Tabela 2). As ofertas de forragem de $16 \%$ durante todo o ano e $16 \%$ PV na primavera e $12 \%$ PV no verão/outono/inverno promoveram os maiores valores de massa de forragem e altura média, o que indica que, nestes sistemas de manejo, a pastagem apresenta maior frequência de pontos amostrais (que podem ser considerados sítios de pastejo) em faixas de altura e massa de forragem que possibilitam maior exploração do potencial de consumo animais. A forma como esta quantidade (massa) de forragem é apresentada aos animais em pastejo (estrutura) é o principal determinante da velocidade de aquisição de nutrientes pelos animais (Carvalho et al., 2001). A estratégia de manejo com oferta de forragem de $8 \%$ na primavera e $12 \%$ no verão/outono/inverno - que possibilitou probabilidade de estro aos 28 meses semelhante à obtida com oferta de $16 \%$ PV durante todo o ano e de $16 \%$ na primavera e $12 \%$ no verão/outono/inverno - foi também a única abaixo de $16 \% \mathrm{PV}$ que possibilitou massa de forragem e altura do pasto próximas às reportadas por Gonçalves \& Carvalho (2006) como estruturas ótimas à ingestão animal. Contudo, as novilhas mantidas com essas ofertas de forragem (16, 16-12 e 8-12\%) apresentaram peso médio de 283, 271 e $273 \mathrm{~kg}$ de PV aos 28 meses, que não diferiram dos obtidos com as demais ofertas de forragem.

A probabilidade de estro obtida com oferta de forragem de $12 \%$ na primavera e $8 \%$ PV no verão/outono/inverno dos 26 para 28 meses manteve-se igual, enquanto aquela obtida com a oferta de forragem de $8 \%$ na primavera e $12 \%$ no verão/outono/inverno e $16 \%$ na primavera e $12 \%$ no verão/ outono/inverno aumentou de 0,25 para 0,50 e de 0,50 para 0,86 , respectivamente. Isso reflete a diminuição, para $8 \%$, no início do verão na oferta de forragem de $12 \%$ na primavera e 8\% no verão/outono/inverno. Esse nível é considerado mais limitante ao consumo e não ocorre com oferta de forragem de $16 \%$ na primavera e $12 \%$ no verão/outono/ inverno, pois a redução ocorre para $12 \%$ no verão, quando o nível de oferta de forragem é o mais favorável ao desempenho animal (Pallarés et al., 2005). O resultado semelhante entre as estratégias de $8 \%$ na primavera e $12 \%$ no verão/ outono/inverno e de $16 \%$ na primavera e $12 \%$ no verão/ outono/inverno provavelmente está relacionado ao fato de que, em ambas as combinações em três estações do ano, se trabalha no nível de $12 \%$ de oferta de forragem.

As estratégias de manejo da oferta de forragem em pastagem natural provocaram mudanças na quantidade e estrutura do pasto em pastagens manejadas exclusivamente com ajuste de lotação. Entretanto, essas alterações não ocasionaram diferenças no desenvolvimento corporal das novilhas aos 24, 26 e 28 meses de idade, o que ocorreu somente na probabilidade de estro aos 28 meses de idade. Esse resultado parece estranho, pois esperava-se que as melhores estratégias provessem melhores ganhos. A 
magnitude das diferenças nas características estruturais do pasto são mais evidentes que no desempenho animal, desta forma, na amplitude de variação entre $8 \%$ e $16 \%$ de oferta de forragem, as mudanças estruturais são compensadas pelo comportamento de pastejo dos animais.

Os cenários moldados ao longo dos anos por essas estratégias de manejo da oferta de forragem (entre $8 \%$ e $16 \%)$ se modificam basicamente em massa de forragem, altura do pasto e área efetivamente pastejada.

Enquanto a oferta de forragem de 8\% durante todo o ano resulta em maior área efetivamente pastejada, a massa de forragem e a altura do pasto são um pouco menores nas demais ofertas de forragem (excluindo-se a de $4 \%$ durante todo o ano). As ofertas de forragem mais elevadas e suas combinações promovem altura do pasto e massa de forragem mais elevadas, porém a área efetivamente pastejada reduz com o aumento no percentual de espécies e/ou na estrutura indesejável promovida pela menor intensidade de pastejo. Dessa forma, o animal compensa, na amplitude de oferta de forragem entre 8 e $16 \%$, as diferenças estruturais, definindo sua estratégia de forrageamento em cada estratégia de manejo de oferta de forragem, o que resulta em desempenho muito parecido.

O baixo peso aos 15 meses de idade contribuiu para o atraso na atividade cíclica regular das novilhas, a qual não foi detectada em nenhumas das estratégias de manejo aos 20 e 24 meses de idade - as primeiras manifestações de estro foram observadas somente aos 26 meses. A partir desses resultados, pode-se afirmar que, para novilhas com baixo peso ao sobreano, as melhores estratégias de manejo da oferta de forragem promoveram diferenças somente na aptidão reprodutiva de novilhas aos 28 meses de idade, o que representa o fim da estação de acasalamento nos sistemas pecuários do Rio Grande do Sul. Para que essa resposta fosse obtida até os 24-26 meses, duas alternativas evidentes, ou pelo menos uma delas, poderiam ter sido utilizadas: que o peso aos 12-14 meses estivesse acima de 220-230 kg; ou que outras estratégias de manipulação da estrutura do pasto fossem incorporadas de forma a aumentar as taxas de ganho de peso, como novas combinações de oferta de forragem, roçadas, diferimento, fertilização, ou uma estratégia de suplementação a pasto que promovesse maior ganho médio diário na recria destas novilhas.

\section{Conclusões}

Nenhuma das estratégias de manejo da oferta de forragem testada permite que as novilhas apresentem atividade cíclica regular aos 24 meses de idade quando o peso vivo for baixo aos 12 meses de idade. O manejo com oferta de forragem de $4 \%$ do peso vivo durante todo o ano promove perda de peso acentuada no verão e no outono, que se torna ainda maior sob condições climáticas adversas, aumentando a perda de peso e da condição corporal. Estratégias de manejo da oferta de forragem que condicionam estruturas de pasto mais favoráveis à ingestão - com oferta de forragem de 16\% durante todo o ano; $16 \%$ na primavera e $12 \%$ no verão/ outono/inverno; e $8 \%$ na primavera e $12 \%$ no verão/outono/ inverno - aumentam a probabilidade de aptidão reprodutiva das novilhas aos 28 meses de idade.

\section{Agradecimentos}

À Empresa Agropecuária Cerro Coroado, pela concessão dos animais; à professora Monica Cadenazzi da Universidad de la Republica do Uruguay, pela importante contribuição nas análises estatísticas; ao Laboratório de Reprodução Animal da Universidade Federal do Rio Grande do Sul, na pessoa do professor Ricardo Macedo Gregory e dos alunos Diego Moreira de Azeredo e Andrei Beskow, pelo auxílio nas coletas de sangues e orientação no diagnóstico da aptidão reprodutiva das novilhas; ao Laboratório Valleé, por intermédio da empresa Vet Brasil, pela parceria no fornecimento de vacinas e vermífugos aos animais; e aos integrantes do Grupo de Pesquisa em Ecologia de Pastejo (GPEP), pelo auxílio prestado na condução e finalização deste trabalho.

\section{Literatura Citada}

BARCELLOS, J.O.J.; PRATES, E.R.; LÓPEZ, J. et al. Influência da estrutura corporal na idade à puberdade de novilhas Braford. In: REUNIÃO DA SOCIEDADE BRASILEIRA DE ZOOTECNIA, 38., 2001, Piracicaba. Anais... Piracicaba: Fundação de Estudos Agrários Luiz de Queiroz, 2001. p.397-398.

BARTHRAM, G.T. Experimental techniques: the HFRO sward stick. In: BARTHRAM, G.T. (Ed.) Hill Farming Research Organization. [S.I.]: n/Biennial Report, 1985. p.29-30.

BAUMONT, R.; GINANE, C.; GARCIA, F. et al. How herbivores optimize diet quality and intake in heterogeneous pastures, and the consequences for vegetation dynamics. In: MILNE, J.A. (Ed.) Pastoral systems in marginal environments. Glasgow: 2005. p.39-50.

BERETTA, V.; LOBATO, J.F.P. Sistema "um ano" de produção de carne: Avaliação de estratégias de alimentação hibernal de bezerras de reposição. Revista Brasileira de Zootecnia, v.27, n.1, p.157-163, 1998.

BERGAMASCHI, H.; GUADAGNIN, M.R.; CARDOSO, L.S. et al. Clima da Estação Experimental da UFRGS (e Região de Abrangência). Porto Alegre: Universidade Federal do Rio Grande do Sul, 2003. 78p.

BRISKE, D.D.; DERNER, J.D.; BROWN, J.R. et al. Rotational grazing on rangelands: Reconciliation of perception and experimental evidence. Rangeland Ecology and Management, v.61, p.3-17, 2008. 
CARVALHO, P.C.F.; RIBEIRO FILHO, H.M.N.; POLI, C.H.E.C. et al. Importância da estrutura da pastagem na ingestão e seleção de dietas pelo animal em pastejo. In: PEDREIRA, C.G.S.; DA SILVA, S.C. (Eds.) A produção animal na visão dos brasileiros. Piracicaba: Fundação de Estudos Agrários Luiz de Queiroz, 2001. p.853-871.

CARVALHO, P.C.F.; FISCHER, V.; SANTOS, D.T. et al. Produção animal no bioma campos sulinos. Revista Brasileira de Zootecnia, v.35, p.156-202, 2006 (supl. especial).

CARVALHO, P.C.F.; SANTOS, D.T.; NEVES, F.P. Oferta de forragem como condicionadora da estrutura do pasto e do desempenho animal. In: SIMPÓSIO DE FORRAGEIRAS E PRODUÇÃO ANIMAL: SUSTENTABILIDADE PRODUTIVA DO BIOMA PAMPA, 2., 2007, Porto Alegre. Anais... Porto Alegre: Universidade Federal do Rio Grande do Sul, 2007. p.23-59.

CRANCIO, L.A.; CARVALHO, P.C.F.; NABINGER, C. et al. Ganho de peso de novilhas em pastagem nativa da Serra do Sudeste do RS submetida ao controle de plantas indesejáveis e intensidades de pastejo. Ciência Rural, 36, n.4, p.1265-1271, 2006.

ESCOSTEGUY, C.M.D. Avaliação agronômica de uma pastagem natural sob níveis de pressão de pastejo. 1990. $231 \mathrm{f}$. Dissertação (Mestrado em Zootecnia) - Faculdade de Agronomia, Universidade Federal do Rio Grande do Sul, Porto Alegre, 1990.

FONTOURA JR., J.A; CARVALHO, P.C.F.; NABINGER, C. et al. Produção animal em pastagem nativa submetida ao controle de plantas indesejáveis e a intensidades de pastejo. Ciência Rural, v.37, n.1, p.247-252, 2007.

GONÇALVES, E.N. Comportamento ingestivo de bovinos e ovinos em pastagem natural da Depressão Central do Rio Grande do Sul. 2007. 131f. Tese (Doutorado em Zootecnia) Faculdade de Agronomia, Universidade Federal do Rio Grande do Sul, Porto Alegre, 2007.

GONÇALVES, E.N.; CARVALHO, P.C.F. Como a estrutura do pasto afeta a ingestão de forragem numa pastagem natural? In: REUNIÃO DO GRUPO TÉCNICO EM FORRAGEIRAS DO CONE SUL GRUPO CAMPOS, 21., 2006, Pelotas. Anais... Pelotas: GTFCSGC, 2006. (CD-ROM).

GORDON, I.J. Plant-animal interactions in complex communities: from mechanism to modelling. In: HODGSON J.; LEMAIRE, G.; MORAES, A. et al. (Eds.). Grassland ecophysiology and grazing ecology. Wallingford: CAB International, 2000. p.191-207.

GREER, R.C.; WHITMAN, R.W.; STAIGMILLER, R.B. et al. Estimating the impact of the management decisions on the occurrence of puberty in beef heifers. Journal of Animal Science, v.56, p.30, 1983.

LOBATO, J.F.P. A "vaca ideal" e o seu manejo em sistemas de produção de ciclo curto. In: SIMPÓSIO DA CARNE BOVINA: DA PRODUÇÃO AO MERCADO CONSUMIDOR, 2003, São Borja. Anais... Porto Alegre, 2003. p.9-43.

LOWMAN, B.G., SCOTT, N., SOMERVILLE, S. Condition scoring beef cattle. Edinburgh: East of Scotland College of Agriculture, 1973. 8p.

MARASCHIN, G.E. Evolução e potencial produtivo da pastagem nativa da Depressão Central submetida a níveis de pressão de pastejo. In.: REUNION DEL GRUPO TECNICO REGIONAL DEL CONO-SUR EM MEJORAMIENTO Y UTILIZACION DE LOS RECURSOS FORRAJEROS DEL AREA TROPICAL Y SUBTROPICAL, 9., 1988. Tacuarembó. Anais... Tacuarembó: 1988. p.65.

MARASCHIN, G.E. Production potential of South American grasslands. In: INTERNATIONAL GRASSLAND CONGRESS, 19., 2001, Piracicaba. Proceedings... Piracicaba: Escola Superior de Agricultura Luzi de Queiroz, 2001. p.5-18.

MARRIOTT, C.A.; CARRÈRE, P. Structure and dynamics of grazed vegetation. Annales de Zootechnie, v.47, p.359-369, 1998.
MOOJEN, E.L.; MARASCHIN, G.E. Potencial produtivo de uma pastagem nativa do Rio Grande do Sul submetida a níveis de oferta de forragem. Ciência Rural, v.32, n.1, p.127-132, 2002.

MORAES, A.; MOOJEN, E.L.; MARASCHIN, G.E. Comparação de métodos de estimativa de taxa de crescimento em uma pastagem submetida a diferentes pressões de pastejo. In: REUNIÃO ANUAL DA SOCIEDADE BRASILEIRA DE ZOOTECNIA, 27. 1990, Campinas. Anais... Piracicaba: Fundação de Estudos Agrários Luiz de Queiroz, 1990. p.332.

MOTT, G.O.; LUCAS, H.L. The design conduct and interpretation of grazing trials on cultivated and improved pastures. In: INTERNATIONAL GRASSLAND CONGRESS, 6., 1952, Pensylvania. Proceedings... Pensylvania: State College Press, 1952. p.1380-1395.

PALLARÉS, O.R.; BERRETTA, E.J.; MARASCHIN, G.E. The South American campos ecosystem. In: SUTTIE, J.; REYNOLDS, S.G.; BATELLO, C. (Eds.) Grasslands of the world. Rome: FAO, 2005. p.171-179.

PILAU, A.; LOBATO, J.F.P. Recria de bezerras com suplementação no outono e pastagem cultivada no inverno. Revista Brasileira de Zootecnia, v.35, n.6, p.2388-2396, 2006.

PINTO, C.E.; CARVALHO, P.C.F.; FRIZZO, A. et al. Comportamento ingestivo de novilhos em uma pastagem nativa do Rio Grande do Sul. Revista Brasileira de Zootecnia, v.36, n.2, p.319-327, 2007.

ROCHA, M.G.; RESTLE, J.; PILAU, A. et al. Produção animal e retorno econômico da suplementação em pastagem de aveia preta e azevém. Ciência Rural, v.33, n.3, p.85-93, 2003.

ROCHA, M.G.; PILAU, A.; SANTOS, D.T. et al. Desenvolvimento de bezerras de corte submetidas a diferentes sistemas alimentares. Revista Brasileira de Zootecnia, v.33, n.6, p.2123-2131, 2004 (supl.2).

SANTOS, D.T.; CARVALHO, P.C.F.; FREITAS, F.K. et al. Adubação de pastagem natural no Sul do Brasil. 1. Efeito do nitrogênio sobre a produção primária. In: GRASSLAND ECOPHYSIOLOGY AND GRAZING ECOlOGY, 2., 2004, Curitiba. Proceedings... Curitiba: UFPR: Macromedia, [2004]. (CD-ROM).

SANTOS, D.T. Manipulação da oferta de forragem em pastagem natural: efeito sobre o ambiente de pastejo e o desenvolvimento de novilhas de corte. 2007. 259f. Tese (Doutorado em Zootecnia) - Faculdade de Agronomia, Universidade Federal do Rio Grande do Sul, Porto Alegre, 2007.

SOARES, A.B. Efeito da dinâmica da oferta de forragem sobre a produção animal e de forragem em pastagem natural. 2002. 197f. Tese (Doutorado em Zootecnia) - Faculdade de Agronomia, Universidade Federal do Rio Grande do Sul, Porto Alegre, 2002.

SOARES, A.B.; CARVALHO, P.C.F.; NABINGER, C. et al. Produção animal e de forragem em pastagem nativa submetida a distintas ofertas de forragem. Ciência Rural, v.35, n.5, p.1148-1154, 2005.

STATISTICAL ANALYSIS SYSTEM - SAS. SAS/STAT user's guide: statistics. 4.ed. Version 6, Cary: 2001, v.2. 943p.

STUTH, J.W. Foraging behavior. In: HEITSCHMIDT, R.K.; STUTH, J.W. (Eds.) Grazing management: an ecological perspective. Oregon: Timber Press, 1991. p.85-108.

WILM, H.G.; COSTELLO, D.F.; KLIPPLE, G.E. Estimating forage yield by the double sampling methods. Journal of American Society of Agronomy, v.36, p.194-203. 1944.

WILTBANK, J.N.; ROBERTS, J.N.; ROWDEN, L. Reproductive performance and profitability of heifers fed to weigh 272 or $318 \mathrm{~kg}$ at the start of the first breeding season. Journal of Animal Science, v.60, n.1, p.25-35, 1985.

WOLFINGER, R. Covariance structure selection in general mixed models. Communication in Statistics, v.22, p.1079-1106, 1993. 